\title{
B Y V EN INTERIOR DE PALABRA (POSICIÓN NO INTERVOCÁLICA) DURANTE LOS SIGLOS XIII, XIV Y XV
}

1. Desde el año 1950 a esta parte, han sido varios y muy importantes los trabajos que acerca de la confluencia $B=V$ se han venido realizando ${ }^{1}$. Desde distintas posiciones teóricas, se ha intentado explicar el porqué de ese cambio fonológico atendiendo, de manera insistente, a las posiciones que tuvieron una mayor importancia en el desarrollo del proceso: inicial e intervocálica. Sin embargo, apenas se le ha prestado atención a la posición interior de palabra no intervocálica.

Es nuestra intención en este estudio observar qué grafías ( $b$ o $v)$ se solían emplear en este contexto durante los siglos XIII, XIV y xV, el porqué de su aparición, qué fonema representan en cada conterto y en qué medida la aparición de una $u$ otra refleja el abandono de la oposición $/ \mathrm{b} /-/ \mathrm{v} /$ durante este período de la Edad Media. No obstante, hay que hacer una aclaración previa. El análisis que elaboraremos no pretenderá ser exhaustivo, sino simplemente indicativo. En realidad, nuestra labor va a consistir en realizar un muestreo sobre unos usos concretos. Las conclusiones que obtengamos serán una primera aproximación en espera de un trabajo informatizado en el que se despoje el mayor número posible de obras correspondientes a la época señalada.

\footnotetext{
1 Vid. Bibliografía.
} 
2. Los textos despojados para este trabajo han sido los siguientes:

- Para el siglo XIII: El Setenario ${ }^{2}$ y la Primera Crónica General de España ${ }^{3}$ de Alfonso X.

- Para el siglo XIV: El Libro de Buen Amor de Juan Ruiz ${ }^{4}$ y dos documentos notariales: uno de Burgos (1367) y otro de Toledo (1349) ${ }^{5}$.

- Para el siglo XV: La Tragicomedia de Calixto y Melibea de Fernando de $\operatorname{Rojas}^{6}$ y el Capítulo 258 de la Crónica Sarracina de Pedro del Corral ?.

Tal vez se pueda argumentar, y con razón, que son pocos textos y algo distintos entre sí, pero no se olvide que se trata de un simple muestreo, de una primera aproximación.

Pasemos ya a exponer los resultados de nuestra lectura.

3. Centraremos nuestra atención en el comportamiento de las grafías $b$ y $v$ en tres tipos de contextos:

A. En contacto con consonante líquida.

$B$. En contacto con consonante nasal.

C. En contacto con otras consonantes.

Nos estamos refiriendo siempre a posición interior de palabra. 1945.

2 Hemos trabajado sobre la edición de Kenneth H. Vanderford, Buenos Aires,

3 Debido al tamaño de la obra, decidimos despojar los capítulos seleccionados por A. García Solalinde para su Antología de Alfonso $X$ el Sabio (5. ${ }^{\mathrm{a}}$ ed., Madrid, Espasa-Calpe, 1965). Ahora bien, el texto de la Primera Crónica General de España que hemos utilizado ha sido el que publicó Ramón Mentendez Pidal (Madrid, Gredos, 1955).

- Edición crítica de J. Corominas, Madrid, Gredos, 1973.

- El documento de Toledo es el "Testamento de Alfonso, hijo de Martín". El de Burgos es "El rey Enrique II confirma al monasterio de Arlanza sus privilegios". Ambos están recogidos en Documentos lingüisticos de España, I. Reino de Castilla, editado por Ramón Menéndez Pidal, Madrid, Anejo LXXXIV de la R. F. E., 1965 (números 295 y 206 , respectivamente).

- Hemos despojado la edición crítica de M. Criado de Val y G. D. Trotter (2. ed., Madrid, C. S. I. C., 1965), para la cual se tomó como base la edición del año 1502, que apareció en Sevilla con el título Libro de Calixto y Melibea y de la puta vieja Celestina. También hemos atendido a la edición de 1499 , a través de L. Kasten y J. Anderson, Concordance to the Celestina (1499). The Hispanic Seminary of Medieval Studies and the Hispanic Society of America, Madison, 1967.

7 Capítulo recogido por Mentendez Pidal en su Crestomatía del español medieval, II, Madrid, 1966. 
4. A. En contacto con consonante líquida.

Hay que distinguir entre consonante líquida antepuesta y pospuesta. La primera es, sin duda, la que presenta una mayor complejidad de estudio. Comenzaremos observando el comportamiento de $b$ y $v$ precedidas de consonante líquida.

5. De los textos del siglo xiII despojados, hemos obtenido, salvo error $\mathbf{u}$ omisión, los siguientes datos (cuando aparezca un verbo en infinitivo, éste englobará las formas del resto de la conjunción, siempre que no varien las grafías $b-v$ o su contexto):

-RB- > -ru-: Acerua, aruoles, barua, destoruar, destoruo, ssoberuia, yerua.

$-\mathrm{RB}-\mathrm{r}=-r b-:$ Algarbe, vierbo, yerba.

$-\mathrm{RV}->-r b-:$ corbo.

$-\mathrm{RV}-$ = -ru-: ceruizes, sseruicio, sseruidunbre, seruir, sieruos, ssoluer, coruo.

-LB- > -lu-: alua, Aluarrezen, aluedriar ( $<$ ARBĭTRIARI), aluedrio, aluoreçe, oluidar.

-LB- $=-l b-:$ Albia.

$-\mathrm{LV}->-l b-$ :

$-\mathrm{LV}-=-l u-:$ abssoluer, asoluimiento, boluer, boluimiento, caluo, enboluer, poluo, rreboluer, saluo, (s)aluo, ssaluaçión, ssaluador, ssaluamiento, ssoluer, uoluer.

6. En los textos del siglo xIV también hemos encontrado vocablos en los que, en interior de palabra, aparecen $b$ o $v$ precedidas de líquida :

-RB- > -rv-: barvas, cedierveda, enervolar, ervera, escarva, estorvar, estorvador, garvanços, sobervia, sobervientas, sobervio, bervo, yerva.

-RB- = -rb-: Algarbe, arbol, barbo, barba, barbado, barbuda, carboniento, enturbiar, escarbando, proverbio, ruibarbo, verbo, yerba.

$-\mathrm{RV}->-r b-:$ barbecho, albuerbula.

$-\mathrm{RV}-$ = -rv-: arvejas, barvecho, cervizes, cierva, cuervo, parva, reservar, โ\{aluamjento, servicio, โleruiçio, servidor, servienta, serviente, servir, siervo, sierva. 
-LB- > -lv-: alua, alvardanes, aluasea,, alvala, alvañar, olvidar, olvido, silvar.

-LB- = -lb-: alba, albarda, albardana, albillo, albo, albogon, alboroçar, albures, alva (adj.), enxalbegar.

$-\mathrm{LV}->-l b-:$ albuerbula.

$-\mathrm{LV}-=-l v-:$ abolver, assolver, atalvina, boluer, desbolver, embolver, malva, polvo, rebolvedor, rebolver, salvaje, salvajina, salva, salvacion, salvador, salvamiento, salvar, salvo.

7. Los casos despojados de los textos del $\mathrm{xv}$ en los que aparecen $b$ y $v$ tras consonante líquida son los siguientes ${ }^{8}$ :

-RB- > -ru-: barua, baruuda, baruiponiente, ensoberuecerse, estoruar, garuines, heruiente, heruir, heruolario, oluidar, soberuio, soruos, toruellinos, turuia, turuino, yerua.

-RB- = -rb-: arbol, barba, barbiponiente, barbuda, borbollones, prouerbio, reuerberar, turbar, turbia, turbo.

$-\mathrm{RV}->-r b-$ :

$-\mathrm{RV}-=-r u-:$ aruejas, ceruiz, cieruo, conseruar, enteruenir, Minerua, peruertir, poruenir, seruicio, seruidor, seruiente, seruir, sieruo, siruiente.

-LB- > -lu-: alua, aluayalde, aluañar, aluarinos, aluorada, oluidar, siluo.

-LB- = -lb-: albarda, albarrana, albañares, alboradas, albricias.

$-\mathrm{LV}->-l b-$ :

$-\mathrm{LV}-=-l u-:$ boluer, emboluer, madreseluia, maluado, maluauiscos, poluo, poluillos, poluorizadas, reboluer, reboluedor, saluado, saluador, saluaje, saluamiento, saluar, saluo.

Se han cotejado las formas recogidas en la Celestina, obra impresa, con datos transcritos de manuscritos ${ }^{\ominus}$ y la proporción de las grafías es prácticamente idéntica.

8 Hay que tener en cuenta que la mayor parte de estos vocablos pertenecen a finales del Xv (1499) y principios del XVI (1502), fechas en que se publicaron las ediciones de La Celestina ya mencionadas.

- Mentendez Pidal (Crestomatía del español medieval). Textos: Enrique De VIllena, Los doze Trabajos de Hércules, de 1417 (n.0 164). Alfonso Martínez De Toledo, Corbacho, de 1438 (n. ${ }^{\circ} 191$ ). Jun Rodriguez de la CAMara, El siervo libre de amor, de 1440 ( $n .^{\circ}$ 193). JuAn DE Mena, Coronación o calacicleos, de 1438 ( $\left.n .^{\circ} 194\right)$. 
8. Con poco que observemos los datos que acabamos de exponer, apreciaremos una mayor presencia de los grupos $r v$ y $l v$, si bien es preciso guardar un margen de error prudencial, puesto que en ello pueden influir varios "azares", como la mayor aparición de palabras con V latina, etc. Pensamos que puede ser interesante comparar las proporciones de estos grupos en la Edad Media con las del español actual ${ }^{10}$.

\begin{tabular}{|c|c|c|c|c|}
\hline & Siglo XIII & Siglo XIV & Siglo $X V$ & 1970 \\
\hline LV & 89 & 72,2 & 80,7 & 50 \\
\hline LB & 11 & 27,8 & 19,3 & 50 \\
\hline RV & 77 & 77 & 75 & 37,1 \\
\hline RB & 23 & 23 & 25 & 62,8 \\
\hline
\end{tabular}

A primera vista, hay algo que nos llama la atención: la relativa homogeneidad que presentan las proporciones de $b$ y $v$ tras liquida durante los siglos XIII, XIV y Xv.

También podemos apreciar, en los datos correspondientes a los textos medievales, una abrumadora presencia de la grafía $v$ tras líquida, especialmente tras $l$. En la actualidad, no sólo no es superior la frecuencia relativa de $v$ tras $l$, sino que $b$ aventaja con claridad a $v$ tras $r$. Los textos medievales muestran una acusada tendencia al empleo de la grafía fonética. La vuelta, a partir de 1726, a la grafía etimológica provocó un notable ascenso en el empleo de $b$ tras $r$ y $l$.

9. En el uso general hispánico, la articulación de las consonantes labiales sonoras (excepto $m$ ) tras líquida es fricativa ${ }^{11}$. Esta misma situación se daba ya en los siglos XIII, xIV y xv. Obsérvese, en la siguiente tabla de datos, que, en relación con las labiales tras líquidas, de los cambios de grafía que se producen, la inmensa mayoría se cumple en la dirección $l b, r b \rightarrow l v, r v$.

\begin{tabular}{|c|c|}
\hline$l b, r b \rightarrow l v, r v$ & $93,75 \%$ \\
\hline$l v, r v \rightarrow l b, r b$ & $6,25 \%$ \\
\hline
\end{tabular}

10 García Camarero ha realizado recuentos sobre las 70.858 palabras del $D R A E$ (1970) con ayuda de un ordenador electrónico. Las frecuencias que aducimos del español actual aparecen en el artículo de Garcfa Camarero titulado "Algunos datos cuantitativos del español", en $L E A$, III (1981), págs. 337-358.

11 Vid., p. ej., Manuel Alvar, "Polimorfismo y otros aspectos fonéticos en el habla de Santo Tomás de Ajusco, México", Anuario de Letras, XI (1966-67), págs. 11-42. También Mentendez Pidal, Manual de gramática histórica española, 15." ed., Madrid, Espasa-Calpe, 1977, pág. 114, n. 1. 


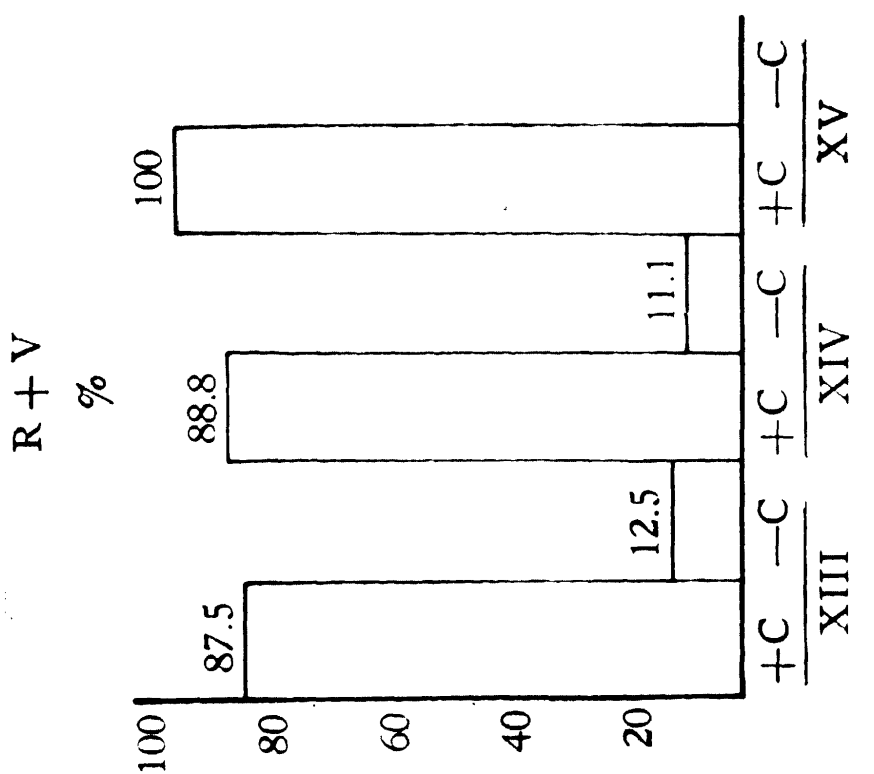

29

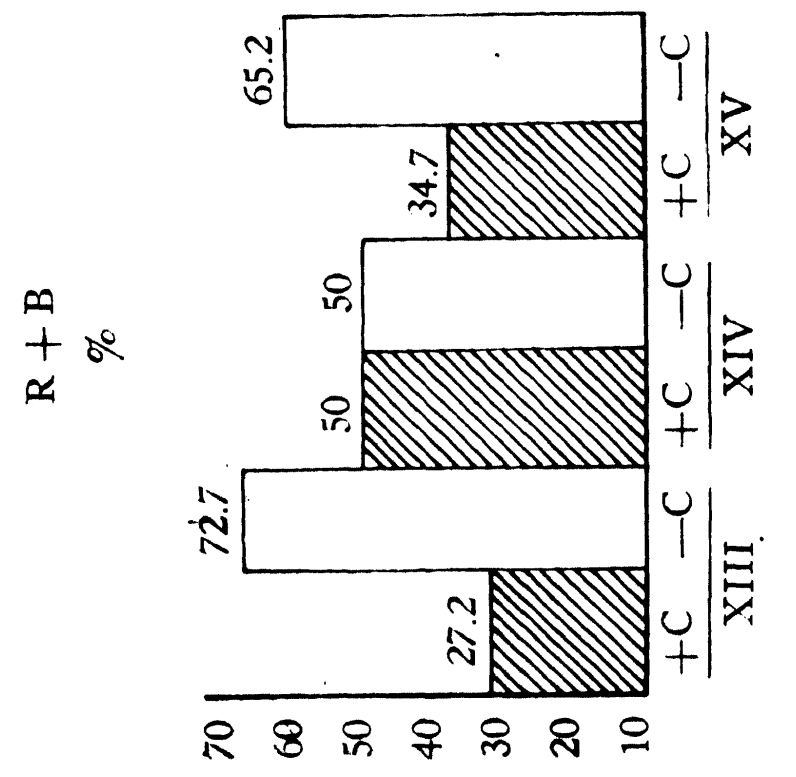

ò

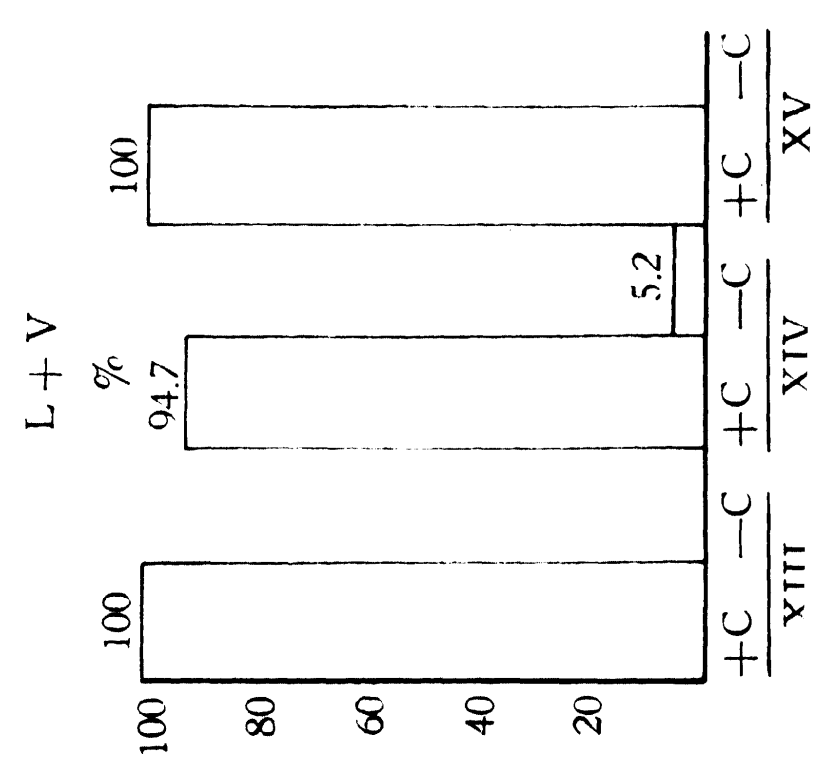

$\therefore$

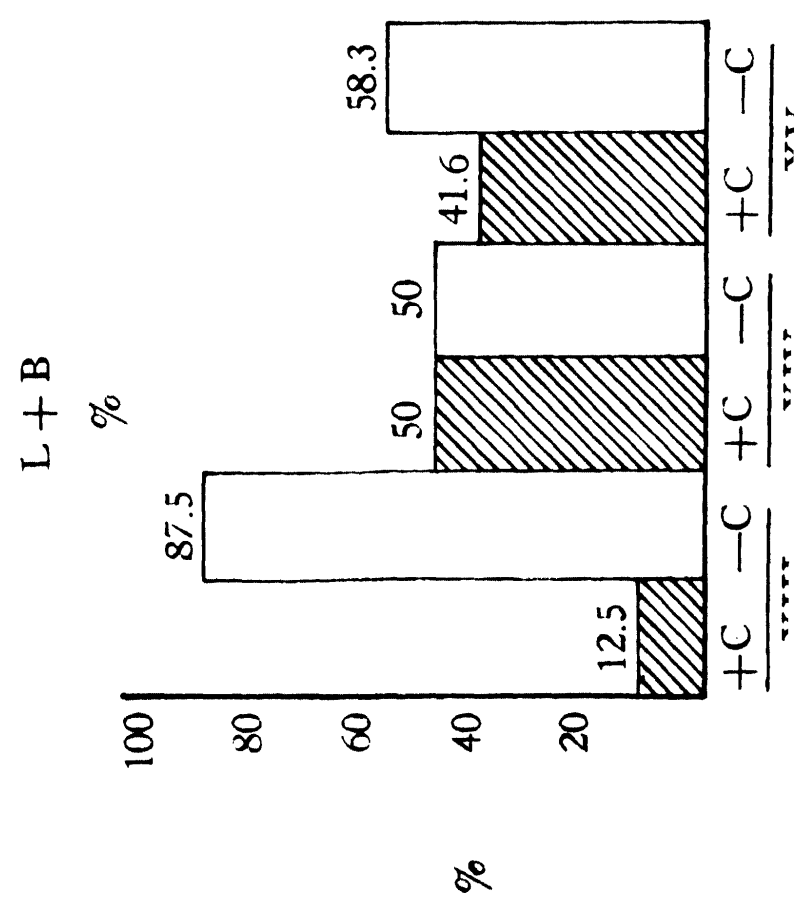


Evidentemente, esto se complementa con el hecho de que la grafía $v$ era mucho más conservada, respecto de la latina, que $b$. Estos datos pueden considerarse como un factor relevante más del carácter fricativo del contexto.

Los casos de conservación de la grafía latina $b$ (tras $r$ o $l$ ) no son nada despreciables (en un $30 \%$ de los casos, $b$ se conserva), pero no podemos olvidar que, aunque, en la Edad Media, la presión que sobre la ortografía ejercía la etimología latina era muy fuerte, en gran parte de los casos $(63,9 \%)$ acabó por imponerse la grafía que mejor se acomodaba a la realidad fonética.

Una cuestión que merece la pena ser estudiada es la relativa a la proporción "conservación" ( $+\mathrm{C}) /$ "no conservación" (-C) de las grafías $b$ y $v$ tras líquida (véanse los histogramas elaborados a partir de los datos recopilados). Hallando las medias de estos datos parciales, podemos comprobar lo siguiente :

1. Durante la Edad Media las grafías $b$ y $v$ tras líquida se conservan un $65,6 \%$ de las veces, mientras que no se conservan un $34,3 \%$.

2. La grafía $b$ tras líquida se conserva en un $36 \%$ de los casos, mientras que pasa a $v$ en un $63,9 \%$.

3. La grafía $v$ tras líquida se conserva en un $95,1 \%$ de las ocasiones, mientras que pasa a $b$ en un $4,7 \%$.

En general, existe una tendencia a la conservación, excepto en el caso de RB y LB.

Podríamos establecer un paralelo entre las consonantes $b$ y $v$ intervocálicas y éstas mismas precedidas de líquidas. El contexto fónico en ambos casos favorece la fricación y, consecuentemente, la grafía más utilizada, tanto tras líquida como entre vocales, es la correspondiente a la fricativa. Ahora bien, el paralelismo no es total, puesto que en posición intervocálica no se da tanta variabilidad. Si aparecieran tantas $b / v$ alternando en posición intervocálica como tras líquida, no se podría hablar de distinción. No olvidemos que tras líquida, donde etimológicamente debería aparecer $b$, hay $v$ sólo en un $63,9 \%$ de los casos, mientras que la primera se conserva en un $36 \%$. Incluso se encuentran varios ejemplos de alternancia $b \sim v$ en una misma palabra: yerba $\sim$ yerua (ss. XIII y XIV), barba $\sim$ barua (ss. XIV y xv), escarbando $\sim$ escarua (s. XIV), turbia $\sim$ turuia (s. Xv), etc. Si como se escribe barba $\sim$ barua se hubiera escrito caballo $\sim$ cauallo, ¿dónde estaría la distinción? Estamos, pues, ante unos contextos que exigen una realización fonética determinada (fricativa) y que favorecen la presencia de una 
determinada grafía (v). Ahora bien, el uso de $v$ es mucho más frecuente en posición intervocálica que tras líquida.

De un modo general, podemos decir que, en cuanto al aspecto ahora estudiado, los siglos XIII, XIV y XV presentan una situación relativamente homogénea, en la que se tiende a utilizar con preferencia la grafía $v$ o $u$ para representar un sonido que, tras consonante líquida, era articulado como fricativo.

En cuanto a la repercusión fonológica de estos datos, señalaremos que la articulación fricativa y la grafia $v$, predominante en la Edad Media tras líquida, no pueden ser interpretadas como índice de la confluencia de los fonemas /b/ y /v/.

El profesor Alarcos señala que el sistema medieval toledano fue sustituido, no sólo por razones históricas y sociales, sino porque tenía una serie de puntos débiles que hacían de él un sistema poco económico en el que se establecían unas oposiciones con escaso rendimiento funcional ${ }^{12}$.

La presencia de la grafía $v(<\mathrm{B})$ tras líquida es una prueba más de que el segmento fónico que representa se sentía como fricativo, independientemente de su etimologia, lo cual, a su vez, es un síntoma de que, paulatinamente y cada vez en más contextos, el rendimiento funcional de la oposición /b/ / / / iba descendiendo. Probablemente, ya en el siglo xIII, el segmento labial no era válido para oponer las formas acerbo/acervo en virtud de los rasgos oclusividad/fricatividad ${ }^{13}$.

10. Hemos de centrar nuestra atención en este momento sobre tres vocablos: corbo, barbecho y albuerbula.

El primero fue aducido como ejemplo del cambio $-\mathrm{RV}->-r b$ - en el siglo xIII. Lo encontramos en el Setenario y pensamos que estamos ante un caso claro de confusión de los fonemas /b/ y /v/, ya que, como antes hemos dicho, la dirección del cambio solía ser la inversa, hasta el punto de que, en los textos despojados, no hemos encontrado ningún otro caso de sus mismas características. Corbo ( $<$ CURvum) se encuentra en el siguiente contexto:

Mas ssegunt la nueua ffazesse mas luengo en altura e ençima corbo ${ }^{14}$.

Nos queda la duda de si se trata de un mero error gráfico.

En el Setenario aparecen otros ejemplos de esta misma palabra, pero

\footnotetext{
12 Fonologia española, 4." ed., Madrid, Gredos, 1965, § 159.

18 Nos atrevemos a hacer esta suposición basándonos en la forma Acerua (s. XIII), cuya etimología latina tenía B.

14 Alfonso X, Setenario, pág. 257, lín. 27.
} 
siempre con $u$. Se registra también la grafía $b$ en el siglo xIV: Poema de $Y$ uçuf (Korbo) y Libro de Apolonio (corbo) ${ }^{115}$.

Respecto de barbecho (< VERVACTUM) y albuerbula ( $<$ alwalwala), ambas encontradas en el siglo xiv, hemos de decir que los motivos de la aparición de $b$ tras líquida, en vez de $v$-que sería lo esperado, dado su origen y la naturaleza fricativa del contexto-, no serían de carácter fonológico, sino fonético.

En el primer caso, se puede pensar, con muchas reservas, en razones asimilatorias, aunque hay que tener en cuenta que la $b$ - se atribuye a su vez a disimilación de - v- (en todo caso, la grafía $b$ - no es constante en la Edad Media).

También se ha registrado un vocablo con $v$ (barvecho), que queda justificado etimológica y fonéticamente.

En el segundo caso, las razones serían disimilatorias, ya que es frecuente escribir $b$ cuando esta consonante va seguida de la vocal $u$ o del diptongo ue. Pensemos en las formas abuelo, bueytra, buelco, buelo, etc., aducidas por R. J. Cuervo ${ }^{18}$.

11. Pasemos ahora a comentar los ejemplos de $b$ seguida de consonante líquida.

La grafía más frecuente durante los siglos xIII, xIV y xv para la labial que precede a consonante líquida $(l \circ r)$ fue $b$. Esta $b$ podía responder a varios orígenes :

-B- latina: diablo, durable, abrebar, etc.

-P- latina: abrir, liebre, pueblo, sabrás, etc.

-PR- latinas : abril, cabra, etc.

15 Hemos recogido estos datos en el fichero medieval del C. S. I. C. La ficha correspondiente a Korbo incluía este texto:

$$
\begin{aligned}
& \text { Dixo: no boxkereyo mixfichox de } \\
& \text { loke me dezidex max kaçadme } \\
& \text { el llobo el Kuwal de don benidex } \\
& \text { Ke yo lo fare fablar korbax lax } \\
& \text { xux çerbizex. }
\end{aligned}
$$

Poema Yuçuf, edición de Menéndez Pidal en Revista de Archivos, Bibliotecas y Museos, VII (1902), pág. 123.

La ficha correspondiente a corbo recogía el siguiente fragmento:

$$
\begin{aligned}
& \text { - "Nin he piedes nin manos un otro estentino } \\
& \text { Dos dientes he semmyeros corbos como fozino. } \\
& \text { Fago al que me traye fincar en el camino. } \\
& \text { - } \text { "Tu fablas del ancora», dixo el pelegrino." }
\end{aligned}
$$

Libro de Apolonio, Ed. de Ch. C. MARDEN, Baltimore, 1917-1922, estr. 812.

18 Disquisiciones sobre filología castellana, Buenos Aires, el Ateneo, 1948, pág. 196. 
-BR- latinas: culuebra, fabricar, libra, etc.

-PL- latinas: doblar, doblez, etc.

$b$ romance: certidumbre, costumbre, fembra, hambre, pesadumbre, temblar, etc.

Entre las palabras despojadas, encontramos algunos casos de -vr-, pero nunca de - vl-. Los casos de -vr-a los que nos referimos son formas verbales de futuro imperfecto de indicativo de verbos que en su origen latino poseían -B-, así como formas del condicional de verbos de las mismas características :

Siglo XIII : aura, auran, auras, avrie, avrien, biura, biuria, biurie, deurie.

Siglo XIV: avre, avredes, avrie, avriedes, bevria, devrie.

Siglo xv: aure, auria, deuria.

También presentan -vr-formas verbales de futuro y condicional que en su origen latino tenían -V-intervocálica (siglo xıII: mouras, mouria, uiuras, uiure; siglo $\mathrm{xv}$ : bivras).

La grafía $-\imath-$ o $-v$ - en los verbos que en su origen tenían -B- se explica por razones de analogía con el resto del paradigma, en el que la - $v$-aparece por ir en un contexto intervocálico y, por lo tanto, fricativo. Existe, no obstante, un contraejemplo: abras (siglo xIv). En este caso, la $b$ se debe bien a la fidelidad a la grafía latina (-B-), bien a la analogía con los cientos de palabras que presentaban $b$ ante líquida.

En cuanto a las formas de futuro que presentan $b$ ante consonante líqui$\mathrm{da}$, diremos que en su mayoría proceden de formas latinas que poseían -P-

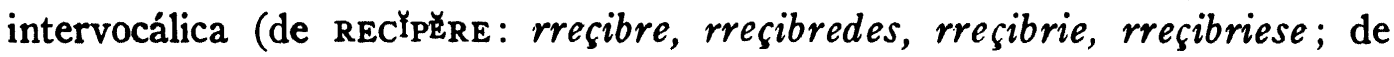
SAPËR: sabras, -n,sabria). Existen otros casos de formas de futuro y condicional que presentan $b$, pero de origen romance (combran, combras, combredes, combrie).

\section{B. En Contacto con Consonante nasal.}

Lógicamente, la nasal aparece precediendo a los elementos labiales $b$ o $v$. En este contexto, $b$ es la grafía de más frecuente aparición. La grafía $v$ tras nasal, en los casos donde aparece, responde a la grafía latina. A pesar de todo, no puede dudarse del carácter oclusivo del fonema que representa (convenir, convento, convertir, enviar, envidia, enveninar, envegeçer, invierno, invisible, etc.). Queremos advertir que, en la conservación de la grafía latina, pudo influir una clara conciencia de composición, cuando esas for- 
mas incluían las partículas con y en ${ }^{17}$. En ocasiones, esa conciencia de composición no era tan evidente y tras las partículas mencionadas se escribía la grafía $b$, correspondiente al fonema bilabial oclusivo sonoro. De ahí que encontremos formas como enbiar y enbolver, por ejemplo.

En los textos medievales despojados aparecen formas no compuestas en las que la grafía fonética le ha vencido el pulso a la grafía etimológica (v.g., embidia, embidioso, combidar y combit).

Existe un caso en el que la grafía de la labial tras consonante nasal ni coincide con su etimología ni corresponde al fonema oclusivo propio de ese contexto. Nos referimos a la forma invierno ( $<$ HIBERNUS).

\section{C. En contacto con otras consonantes.}

Aparte de la posición inicial, de la intervocálica y de las hasta aquí analizadas, hemos encontrado grafías $b$ y $v$ en otros tres contextos (nos referimos siempre a los textos estudiados, correspondientes a los siglos XIII, XIV y XV):

a) En contacto con apicoalveolar.

b) En contacto con dental sonora.

c) En posición implosiva ante consonante palatal.

En cuanto a $b$ y $v$ en contacto con apicoalveolar, hay que señalar que, en los textos medievales despojados, casi siempre se respeta la grafía etimológica, y más teniendo en cuenta que en muchos casos el segmento labial forma parte del morfema prefijal:

Siglo XIII : abssolver, absueltos y desuiar.

Siglo XIV: absolver, absolución, abstinencia, desbarato, desviar, Rocasvalles.

Siglo Xv: absente, abstener, desbanado, desbocado, desbrauar, desuariar, desuarios, desuentura, desienturada, desuenturado, desuergonçado, desuerguença, desuiar, desiio, obsequias, obstar.

Sólo encontramos un caso en que no se respeta la grafía etimológica, pero queda justificado por el fenómeno de la analogía : desbueluete.

También se conserva la grafía latina cuando se presenta $b$ en posición implosiva ante consonante palatal (obiecto y subjeción, siglo $\mathrm{xv}$ ).

En lo que se refiere a $b$ y $v$ en contacto con $d$, debemos distinguir, por

17 Vid. R. J. Cuervo, op. cit., págs. 194-195.

LXVII, $10^{\circ}-2 .^{\circ}-4$ 
un lado, aquellas formas en las que se respeta la grafía latina (v.g., adversario, adversidad, adverso) y, por otro, las palabras que presentan el grupo consonántico romance labial + dental. $\mathbf{P}^{\prime} T, P^{\prime} D, B^{\prime} T$ y $V^{\prime} T$ se agruparon reducidas a $b d$. Según Pidal, esta $b$ todavía era pronunciada por Valdés ${ }^{18}$.

Las formas que hemos recogido en los textos medievales son las siguientes :

Siglo XIII : abdalla, acabdellar, bibda, cabdal, cabdiello, cibdat, cobdiciar, cobdo, debdor, dubdar, rrecabdo.

Siglo xIV: bebdo, cabdal, cibdadano, çibdades, cibdat, cobdicia, cobdiciar, cobdicioso, debdo, dubda, dubdança, dubdar, dubdoso, rebtar, rebtado, recabdar, recabdo, subditos, vibda.

Siglo Xv : cibdad, cobdicia, cobdiciar, cobdiciosa, dubda, dubdes, dubdosa.

En los tres últimos contextos analizados es la grafía etimológica la que predomina de forma absoluta.

14. En nuestra reaproximación a las grafías $b$ y $v$ en posición interior no intervocálica, hemos despojado algunos de los textos más significativos de los siglos XIII, xIV y xV, ya que tales centurias eran las más descuidadas en este aspecto. Hemos distribuido nuestro trabajo atendiendo a los contextos consonánticos, de las características mencionadas, en que $b$ y $v$ solían aparecer: en contacto con líquida, con nasal y, de menor importancia, en contacto con apicoalveolar, dental sonora y palatal.

En líneas generales, podemos decir que las grafías $b$ y $v$, en las posiciones señaladas, poseían un comportamiento homogéneo, aunque comparativamente más irregular que en posición intervocálica.

Respecto de $b$ y $v$ en contacto con líquida, diremos que, cuando esta última precedía a la labial, solían emplearse las grafías $v$ o $u$, debido al carácter fricativo que el contexto confería al sonido que representaban. Como consecuencia de esto mismo, la grafía V etimológica era más conservada que la grafía $B$, que pasaba con frecuencia a $v$ tras líquida. Excepto en este contexto, $b$ y $v$ interiores solían conservarse.

18 Manual de gramática histórica española, \& 601. 


\section{$B Y V E N L A$ EDAD MEDIA}

\begin{tabular}{r|ccc|c} 
& XIII & XIV & XV & \multicolumn{1}{c}{$\bar{X}$} \\
Conser. & 56,8 & 70,8 & 69 & $-65,5 \%$ \\
No conser. & 43,1 & 29 & 30,8 & $-34,3 \%$
\end{tabular}

En cuanto a las grafías que solían aparecer cuando la labial era seguida de líquida, destacaremos que lo normal durante estos siglos fue la utilización de $b$, tal vez por mera tradición gráfica, como en el caso de -ble. Después de consonante nasal, lo más frecuente era la utilización de la grafía que representaba el fonema bilabial oclusivo: $b$. Dada la naturaleza fónica del contexto, el porqué de esa grafía es fácilmente explicable.

Observamos, pues, cómo, precedidas de líquida y de nasal, son las grafías de carácter fonético las que prevalecen sobre las etimológicas. No ocurre lo mismo en contacto con apicoalveolar y palatal, donde el predominio de la grafía latina es absoluto.

\section{BIBLIOGRAFIA}

\section{Obras consultadas.}

Alarcos Llorach, Emilio, Fonología española, 4. ed., Madrid, Gredos, 1965.

Alonso, Amado, De la pronunciación medieval a la moderna en español, I, 2. ed., Madrid, Gredos, 1967.

Alonso, Dámaso, "B $=\mathrm{V}$ en la Península Hispánica", en Obras Completas, I, Madrid, Gredos, 1972, págs. 215-290.

Alvar, Manuel, "Polimorfismo y otros aspectos fonéticos en el habla de Santo Tomás Ajusco, México", Anuario de Letras, VI (1966-67), págs. 11-42.

- (ed.), Vida de Sta. María Egipciaca, Madrid, C. S. I. C., 1970.

(ed.), Libro de Apolonio, Madrid, Castalia, 1976.

Baldinger, Kurt, y Rivarola, José Luis, “Lingüística tradicional y fonología diacrónica", Anuario de Letras, IX (1971), págs. 5-49.

Catalán, Diego, Lingüística ibero-románica, Madrid, Gredos, 1974.

Cuervo, Rufino José, Disquisiciones sobre filología castellana, Buenos Aires, el Ateneo, 1948.

Galmes DE Fuentes, Alvaro, “El arcaísmo fonológico de los dialectos del norte portugués y su importancia para la lingüística románica general", Boletín de Filología, XX (1961), págs. 19-30.

Garcfa Camarero, Antonio, "Algunos datos cuantitativos del español", LEA, III (1981), págs. 337-358.

Garcfa Solalinde, Antonio, Antología de Alfonso $X$ el Sabio, 5." ed., Madrid, EspasaCalpe, 1965 (Col. Austral, n. ${ }^{\circ}$ 169). 
Grandgent, C. H., Introducción al latín vulgar, traducción y anotaciones de Francisco de B. Moll, 4. ${ }^{a}$ ed., Madrid, C. S. I. C., 1970.

Hanssen, Federico, Gramática histórica de la lengwa castellana, prólogo de Luis Alfonso, París, 1966.

Jakobson, R., "Prinzipien der historischen Phonologie", Travaux du Cercle Linguistique de Praga, IV (1931), págs. 247-267.

JungemanN, F. H., "La confluencia B-V y las consonantes oclusivo-fricativas sonoras del español y del gascón", en La teoría del sustrato y los dialectos hispano-romances y gascones, Madrid, Gredos, 1955, págs. 336-361.

LAPESA, Rafael, Historia de la Lengua española, 8. ${ }^{a}$ ed., Madrid, Gredos, 1980.

Marden, Ch. C. (ed.), Libro de Apolonio, Baltimore, 1917-1922.

Martinet, André, Economía de los cambios fonéticos, Madrid, Gredos, 1974.

Menendez Pidal, Ramón, Manual de gramática histórica española, 15. ${ }^{2}$ ed., Madrid, Espasa-Calpe, 1977.

-, "Poema de Yuçuf", en Revista de Archivos, Bibliotecas y Museos, VII (1902), págs. 91-129, 273-309 y 347-362.

- Crestomatía del español medieval, Madrid, 1966.

Монц, F. George, Introduction a la Chronologie du latin vulgaire, Paris, Librairie Emile Bouillon, 1899.

Navarko Tomás, Tomás, Manual de pronunciación española, 19. ed., Madrid, C. S. I. C., 1977.

OTERo, Carlos-Peregrín, Evolución y revolución en romance, Barcelona, Seix Barral, I, 1971 ; II, 1976.

Parodi, Claudia, "Mutación y confluencia de las oclusivas latinas en romance castellano", Anuario de Letras, X (1972), Méjico, págs. 47-74.

Penny, Ralph J., "The convergence of $\mathrm{B}, \mathrm{V}$ and -P- in the Peninsula: a reappraisal", Medieval Hispanic Studies, A. D. Deyermond (ed.), presented by Rita Hamilton, London, Tamesis Books Limited, 1976, págs. 149-159.

Santiago Lacuesta, R., "Castellano, español y fonología diacrónica", Studia Zamorensia, II (1981), págs. 199-218.

\section{Francisco Moreno Fernández. \\ Universidad de Alcalá de Henares.}

\section{Obras despojadas.}

Alfonso X, Setenario, edición de Kenneth H. Vanderford, Buenos Aires, 1945.

-, Primera Crónica General de España, edición de Menéndez Pidal, Madrid, Gredos, 1955.

Mentendez Pidal, Ramón, Crestomatía del español medieval, II, Madrid, 1966, números $164,173,191,193$ y 194.

- Documentos lingüisticos de España, I. Reino de Castilla, editado por Madrid, Anejo LXXXIV de la RFE, 1965, núms. 206 y 295.

Rojas, Fernando de, Tragicomedia de Calixto y Melibea, edición de M. Criado de Val y G. D. Trotter, 2. ${ }^{2}$ ed., Madrid, C. S. I. C., 1965. También hemos despojado L. KAsTEN and J. Anderson, Concordance to the Celestina (1499), The Hispanic Seminary of Medieval Studies and the Hispanic Society of America, Madison, 1976.

Rurz, Juan, Libro de Buen Amor, edición crítica de J. Corominas, Madrid, Gredos, 1973. 